\title{
Cluster magnetotail observations of a tailward-travelling plasmoid at substorm expansion phase onset and field aligned currents in the plasma sheet boundary layer
}

\author{
N. C. Draper ${ }^{1}$, M. Lester ${ }^{1}$, S. W. H. Cowley ${ }^{1}$, J. A. Wild ${ }^{1}$, S. E. Milan ${ }^{1}$, G. Provan ${ }^{1}$, A. Grocott ${ }^{1}$, A. N. Fazakerley ${ }^{2}$, \\ A. Lahiff ${ }^{2}$, J. A. Davies ${ }^{3}$, J.-M. Bosqued ${ }^{4}$, J. P. Dewhurst ${ }^{2}$, R. Nakamura ${ }^{5}$, C. J. Owen ${ }^{2}$, J. Watermann ${ }^{6}$, \\ M. G. Henderson ${ }^{7}$, H. J. Singer ${ }^{8}$, and E. Donovan ${ }^{9}$ \\ ${ }^{1}$ Radio and Space Plasma Physics Group, University of Leicester, University Road, Leicester, LE1 7RH, UK \\ ${ }^{2}$ Mullard Space Science Laboratory, Holmbury St Mary, Dorking, Surrey RH5 6NT, UK \\ ${ }^{3}$ Space Science and Technology Department, Rutherford Appleton Laboratory, Chilton, Didcot, Oxon OX11 0QX, UK \\ ${ }^{4}$ CESR/CNRS, BP 4346 9, Avenue Colonel Roche, 31028 Toulouse CEDEX 4, France \\ ${ }^{5}$ Space Research Institute, Austrian Academy of Sciences, 8042 Graz, Austria \\ ${ }^{6}$ Danish Meteorological Institute, Copenhagen, Denmark \\ ${ }^{7}$ Los Alamos National Laboratory, Los Alamos, NM 87545, USA \\ ${ }^{8}$ Space Environment Center - National Oceanic and Atmospheric Administration, Boulder, CO 80305, USA \\ ${ }^{9}$ University of Calgary, 2500 University Drive NW, Calgary, Alberta, T2N 1N4, Canada
}

Received: 4 May 2005 - Revised: 12 October 2005 - Accepted: 15 November 2005 - Published: 23 December 2005

\begin{abstract}
We present data from both ground- and spacebased instruments for a substorm event which occurred on 5 October 2002, with an expansion phase onset time of 02:50 UT determined from the ground magnetometer data. During this substorm, the Cluster spacecraft were located around $15 R_{E}$ downtail, $8 R_{E}$ from midnight in the premidnight sector and just $2 R_{E}$ above the equatorial plane (in GSM coordinates). At expansion phase onset the Cluster spacecraft were located in the plasma sheet, tailward of a near-Earth neutral line and detected a significant time delay of $6 \mathrm{~min}$ between the tail field $B_{z}$ component becoming negative and the subsequent detection of Earthward flows. This is explained by the formation of a tailward-directed travelling compression region initially Earthward of the spacecraft; 7 min later the Cluster spacecraft entered the plasma sheet boundary layer; they remained in and close to the plasma sheet boundary layer for around $15 \mathrm{~min}$ before exiting to the lobe. The spacecraft then re-entered the plasma sheet $30 \mathrm{~min}$ after onset. Earthward then tailward directed currents detected in the plasma sheet boundary layer after onset indicate that the Cluster spacecraft encountered the dawnward and duskward portions of the reconnection flow associated current system with Region 1 sense, respectively. The reconnection site and current system were initially skewed towards the pre-midnight sector, consistent with previous observations that found the majority of substorm onsets located
\end{abstract}

Correspondence to: N. Draper

(email: ncd8@ion.le.ac.uk) in this sector. At later times the reconnection site and current system had moved towards dawn, to be located more centrally in the midnight sector.

Keywords. Magnetospheric physics (Magnetosphereionosphere interactions; Magnetospheric configuration and dynamics; Magnetotail boundary layers)

\section{Introduction}

There are currently two main categories of substorm onset model which have been developed. The first of these is the near-Earth neutral line model (NENL; Baker et al., 1996, and references therein). A modified NENL model has also been proposed by Shiokawa et al. (1998). The cross-field current instability model (CCI) proposed by Lui (1996), and references therein, is the second main category of substorm onset model. Each encompasses three phases: the growth phase, the expansion phase, and the recovery phase. The NENL model suggests the spontaneous reconnection of antiparallel magnetic field lines at around 20 to $30 R_{E}$ from Earth in the magnetotail (Nagai et al., 1998), as a result of the magnetotail loading that occurs due to dayside reconnection during the growth phase of the substorm. Closed magnetic field lines of the plasma sheet are reconnected first and then followed by the open field lines of the tail lobes. Newly-closed field lines are returned to the dayside, while tailward of the reconnection site field lines remain connected to the interplanetary 


\section{At 0300 UT}

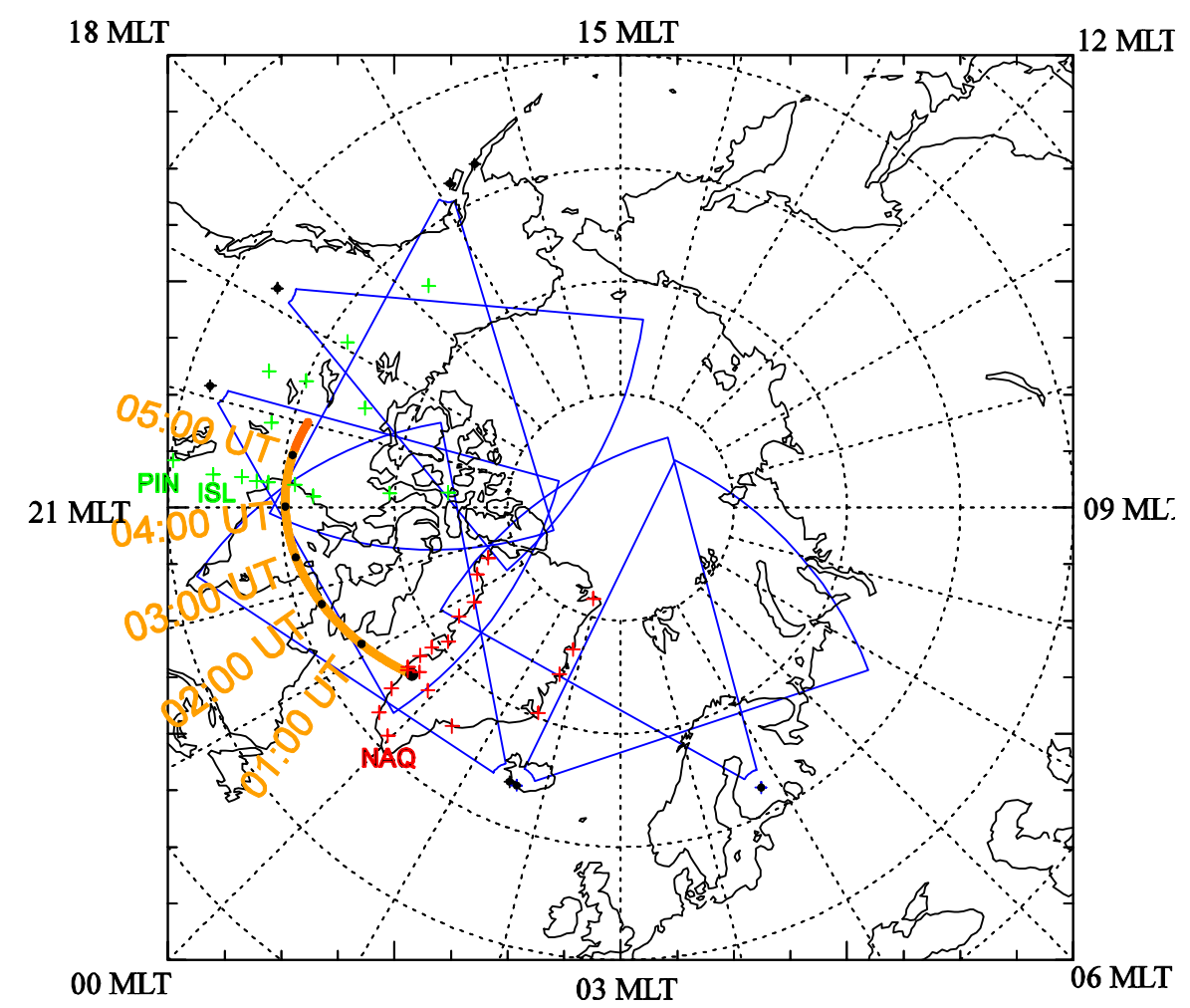

Fig. 1. Northern Hemisphere polar cap within $60 \mathrm{deg}$ at 03:00 UT on 5 October 2002 in geographic coordinates. Magnetic local times (MLT) refer to 03:00 UT locations. Shown in blue are six of the nine SuperDARN radar fields of view from which data are used in this study. In green are the locations of the CANOPUS magnetometer stations, in red those of the Greenland magnetometer stations. The Cluster footprint is shown in orange.

magnetic field (IMF). The reconnection of field lines in this region decreases the current in the central plasma sheet, disturbing the current flow. Excess current is therefore diverted away from the inner current sheet region and redirected into the substorm current wedge (SCW; McPherron et al., 1973). The SCW consists of field-aligned currents directed both into and out of the ionosphere, which are closed in the ionosphere by a westward auroral electrojet and in the tail by a dawnward directed current. The modified NENL model involves braking of high-speed, Earthward ion flow in the region of the Earth's magnetic field that is more dipolar than further downtail. This ion flow is diverted, producing a dawnward inertia current at the boundary between dipolar and tail-like fields. As flux pile-up continues, this boundary moves tailwards; in the modified NENL model, it is at this boundary that the SCW is formed.

A consequence of the formation of a NENL together with the distant neutral line is the formation of a region of entirely closed magnetic flux, or plasmoid. At distances greater than $\sim 30 R_{E}$ downtail plasmoid-type flux ropes from $10 R_{E}$ long have been detected travelling mostly tailward as found in ISEE and Geotail studies (Ieda et al., 1998). Between 20 and $30 R_{E}$ downtail smaller flux ropes of 1 to $5 R_{E}$ in diameter have been detected travelling both Earthward and tailward in equal numbers by Geotail (Slavin et al., 2003). Travelling compression regions (TCRs) are intensifications of the lobe magnetic field caused by the movement of plasmoids within the magnetotail. The presence of the plasmoid forces the lobe magnetic field lines to compress around it, and these compressions appear to move as the plasmoid moves through the tail. TCRs can be detected as perturbations in the northsouth component of the magnetic field, usually bipolar in nature, reflecting the motion of the plasmoid, and by simultaneous enhancements in the intensity of the tail field magnitude. They are typically detected for a few minutes at a time, and both Earthward and tailward-moving TCRs have been observed; Slavin et al. (2005) showed that $20 \%$ of TCRs detected by Cluster within $20 R_{E}$ of Earth were tailward directed whilst the rest were Earthward directed.

The CCI model suggests that current disruption in the near-Earth current sheet at the start of the expansion phase of the substorm is caused by the onset of an instability and a high level of magnetic field fluctuations. The SCW is formed and diverts current into, and back out of, the ionosphere, and the NENL is formed further downtail (at around 20 to $30 R_{E}$ ) as a result. This then allows reconnection of magnetic field lines in the magnetotail. 
Field-aligned currents (FACs; Potemra, 1979; Stern, 1983) consist of two coupled systems: the Region 1 currents, which flow into the ionosphere from the magnetotail in the post-midnight sector, and out of the ionosphere in the premidnight sector; and the Region 2 currents, which are oppositely directed and occur in the ionosphere at lower latitudes. The Region 1 currents are located along the outer edge of the plasma sheet, while the Region 2 currents are located well within the plasma sheet. These currents couple the magnetosphere to the ionosphere and are a consequence of drag imposed on ionospheric plasma particles, colliding with neutral particles, as the magnetic field lines with which they are associated are pulled over the polar caps (Cowley, 2000). The eastward and westward electrojets meet in the Harang discontinuity region, where the Region 1 and 2 currents become hard to distinguish.

Hence, in the NENL model substorm onset is initiated by spontaneous reconnection of magnetic field lines at around 20 to $30 R_{E}$ downtail, while in the CCI model it is the current disruption closer to Earth that is the initiator of substorm onset. In this paper we examine observations from a large number of instruments collecting data in the solar wind, magnetosphere and ionosphere in order to determine the development of a substorm on a large scale. We pay special emphasis on the observations in the tail by Cluster relating the currents measured there to the overall substorm cycle.

\section{Instruments}

Data from various instruments on the four Cluster spacecraft were used in this study. The Fluxgate Magnetometer (FGM; Balogh et al., 1997) provided information about the magnetic field, while the Cluster Ion Experiment (CIS; Rème et al., 1997) and Plasma Electron and Current Experiment (PEACE; Johnstone et al., 1997) instruments provided information about the low energy ions $(0.02 \mathrm{eV}$ to $30 \mathrm{keV})$ and electrons $(0.7 \mathrm{eV}$ to $30 \mathrm{keV})$, respectively. The Research with Adaptive Particle Imaging Detectors (RAPID; Wilken et al., 1997) instrument provided high energy electron (40 to $400 \mathrm{keV}$ ) data from the Imaging Electron Spectrometer (IES) instrument. At the time of interest the Cluster spacecraft were located at around $15 R_{E}$ downtail, $8 R_{E}$ from midnight in the pre-midnight sector and around $2 R_{E}$ above the equatorial plane at a separation of $\sim 1 R_{E}$; Cluster 1 was located closest to midnight, Cluster 2 furthest from midnight, Cluster 3 closest to the equatorial plane, and Cluster 4 was located farthest downtail. Figure 1 presents the position of the magnetic footprint of the Cluster 1 spacecraft on 5 October 2002 between 00:00 and 06:00 UT (orange line) mapped using the Tsyganenko 1996 model (Tsyganenko and Stern, 1996).

Supporting data are available from a number of other sources. The solar wind conditions for this event were detected using the magnetometer instrument (MAG; Smith et al., 1998) and Solar Wind Electron Proton Alpha Monitor instrument (SWEPAM; McComas et al., 1998) on the Advanced Composition Explorer spacecraft (ACE; Stone et al., 1998). The near-Earth $\left(6.6 R_{E}\right)$ downtail conditions were investigated for this event using magnetic field data from a Geostationary Operational Environmental Satellite (GOES8) spacecraft (Nagai et al., 1982) and energetic proton and electron flux data from a Los Alamos National Laboratory (LANL-01A) spacecraft (Belian et al., 1978).

Data from two ground-based magnetometer chains were also used in this study: the Canadian Auroral Network for the Open Program Unified Study (CANOPUS; Rostoker et al., 1995) and the Greenland magnetometer network (FriisChristensen et al., 1985). The CANOPUS magnetometers are located in west-central Canada (green crosses on Fig. 1), while the Greenland magnetometers are located along the eastern and western coasts of Greenland (red crosses on Fig. 1). Magnetometer stations of particular interest are labelled. Unfortunately, data from other magnetometer sites located between CANOPUS and Greenland were not available to provide more comprehensive coverage of this region of the ionosphere, as they were either located at too high a latitude to detect the substorm onset, or had no data available for this interval.

Ground-based data were also used from six of the Northern Hemisphere HF radars (Kodiak, Prince George, Pykkvibær, Hankasalmi, Saskatoon, Stokkseyri; depicted in blue in Fig. 1) of the Super Dual Auroral Radar Network (SuperDARN; Greenwald et al., 1995) radar array. These line-of-sight velocity data were used to obtain ionospheric flows.

\section{Data description}

3.1 Ground magnetometer data, SuperDARN radar data, and IMF conditions

Figure 2 shows data from two selected CANOPUS magnetometer stations, Island Lake (ISL, $64.74^{\circ}$ invariant latitude; 21:00 MLT at 03:30 UT) and Pinawa (PIN, 60.98 ; 21:00 MLT at 03:30 UT), and from the Narsasuaq (NAQ, $66.31^{\circ} ; 01: 30 \mathrm{MLT}$ at 03:30 UT) Greenland station for 5 October 2002, from 02:30 to 04:30 UT. Shown are the $X$ and $\mathrm{Z}$ components of the magnetic field at each station, and the $\mathrm{X}$ and $\mathrm{Z}$ components filtered between 20 and 200 s, providing information on the presence of Pi2 wave activity. The filtered $\mathrm{X}$ component of the magnetic field first detected $\mathrm{Pi} 2$ waves at 02:50 UT, and this time is taken as that of substorm expansion phase onset in the absence of optical data for this event. At 02:52 UT a decrease in the X component at the ISL station and a positive increase in the $\mathrm{X}$ component at PIN were detected. The PIN station also detected a decrease in the $\mathrm{Z}$ component of the magnetic field at this time, whilst ISL detected a gradually decreasing $\mathrm{Z}$ component. Given that both ISL and PIN were located at the same local time we conclude that ISL detected a westward electrojet, and was equatorward of the centre, whilst PIN detected the edge of the eastward electrojet. The NAQ station detected Pi2 pulsations from 02:52 UT. The X component of the magnetic field decreased 


\section{CANOPUS \& Greenland}

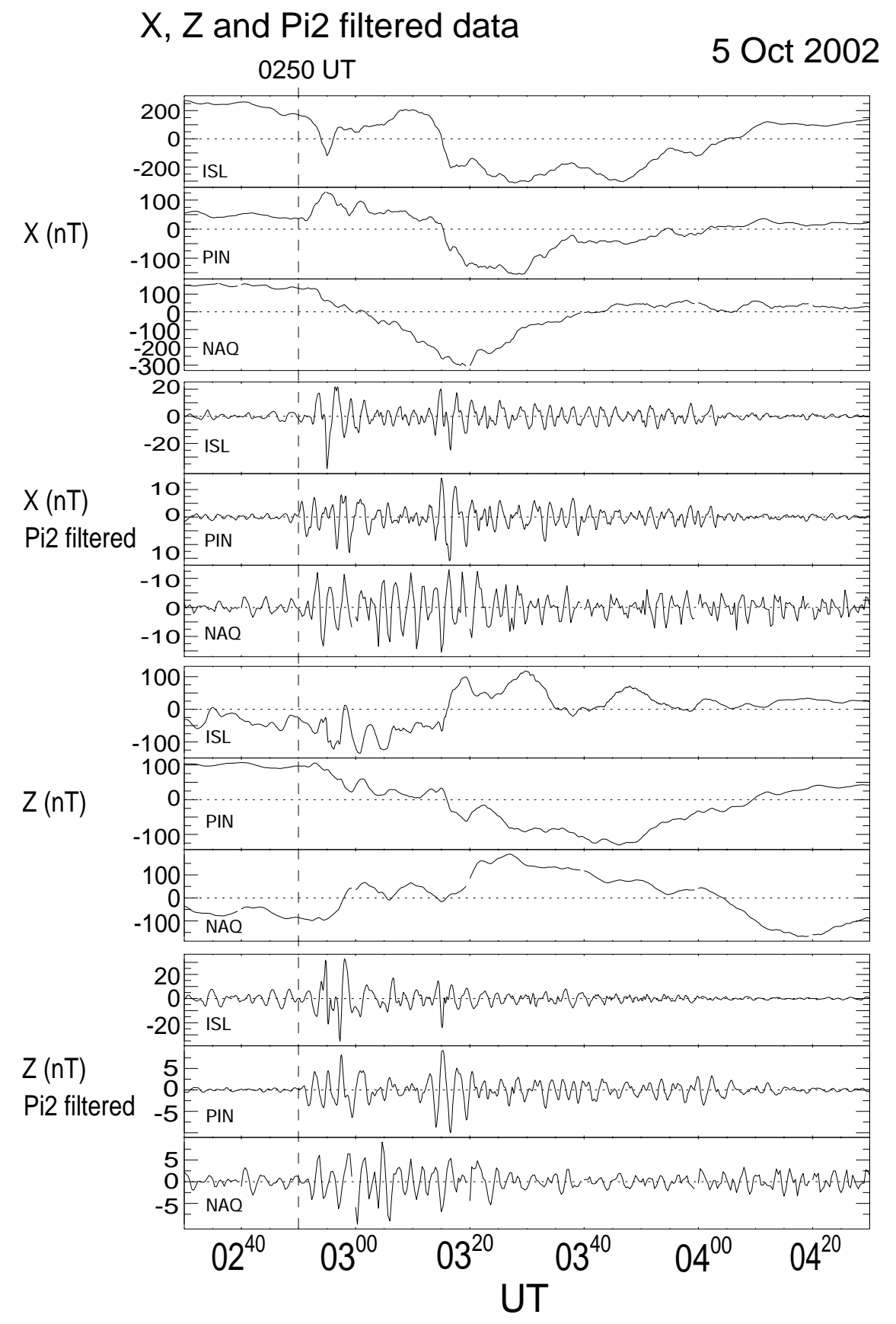

Fig. 2. CANOPUS and Greenland magnetometer data for 5 October 2002, from 02:30 to 04:30 UT, for the Island Lake (ISL), Pinawa (PIN) and Narsarsuaq (NAQ) stations. Panels depict: X component of magnetic field; Pi2 filtered (period band 20 to $200 \mathrm{~s}$ ) X component; Z component of magnetic field; Pi2 filtered Z component. Substorm onset at 02:50 UT is indicated by the vertical dashed line.

from 02:53 UT, indicating detection of the westward electrojet. At onset, the $\mathrm{Z}$ component of the magnetic field was negative, increasing and turning positive around $8 \mathrm{~min}$ after onset. This indicates that the centre of the westward electrojet was located poleward of the NAQ station at onset, and equatorward of the NAQ station from 8 min after onset.
Line-of-sight velocity measurements from six of the $\mathrm{Su}$ perDARN radar array (Kodiak, Prince George, Pykkvibær, Hankasalmi, Saskatoon and Stokkseyri) were available for this interval. They were combined using the map potential analysis technique (Ruohoniemi and Baker, 1998) to produce large-scale global convection maps at two-minute intervals 


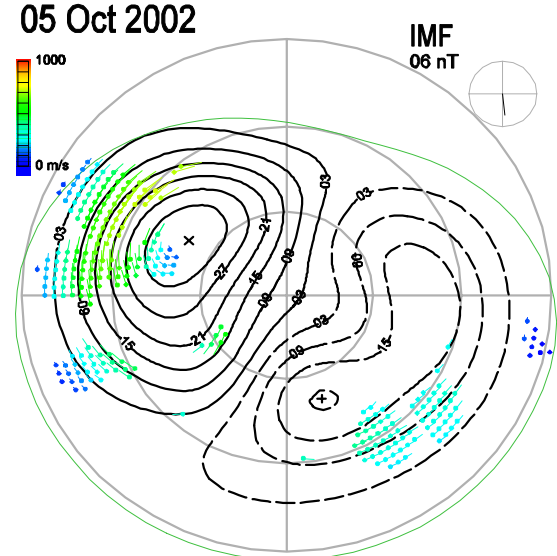

a) 02:50:00 - 02:52:00 UT

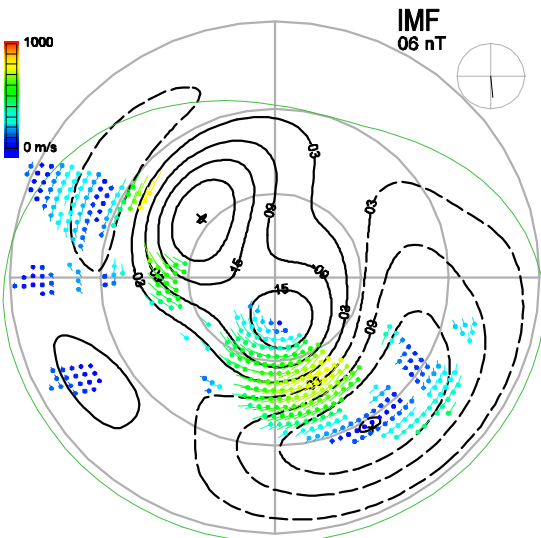

b) 03:14:00 - 03:16:00 UT

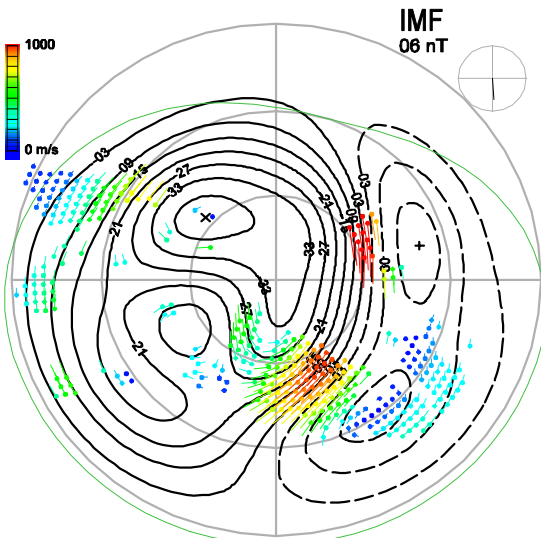

c) 03:20:00- 03:22:00 UT

Fig. 3. SuperDARN map potential plots for 5 October 2002 in the Northern Hemisphere polar cap within 60 deg (geographic coordinates) with IMF value and direction indicated. Noon local time is at the top of the plot. (a) 02:50 to 02:52 UT; (b) 03:14 to 03:16 UT; (c) 03:20 to 03:22 UT.

\section{Advanced Composition Explorer (ACE) MAG \& SWEPAM \\ 5 October 2002}

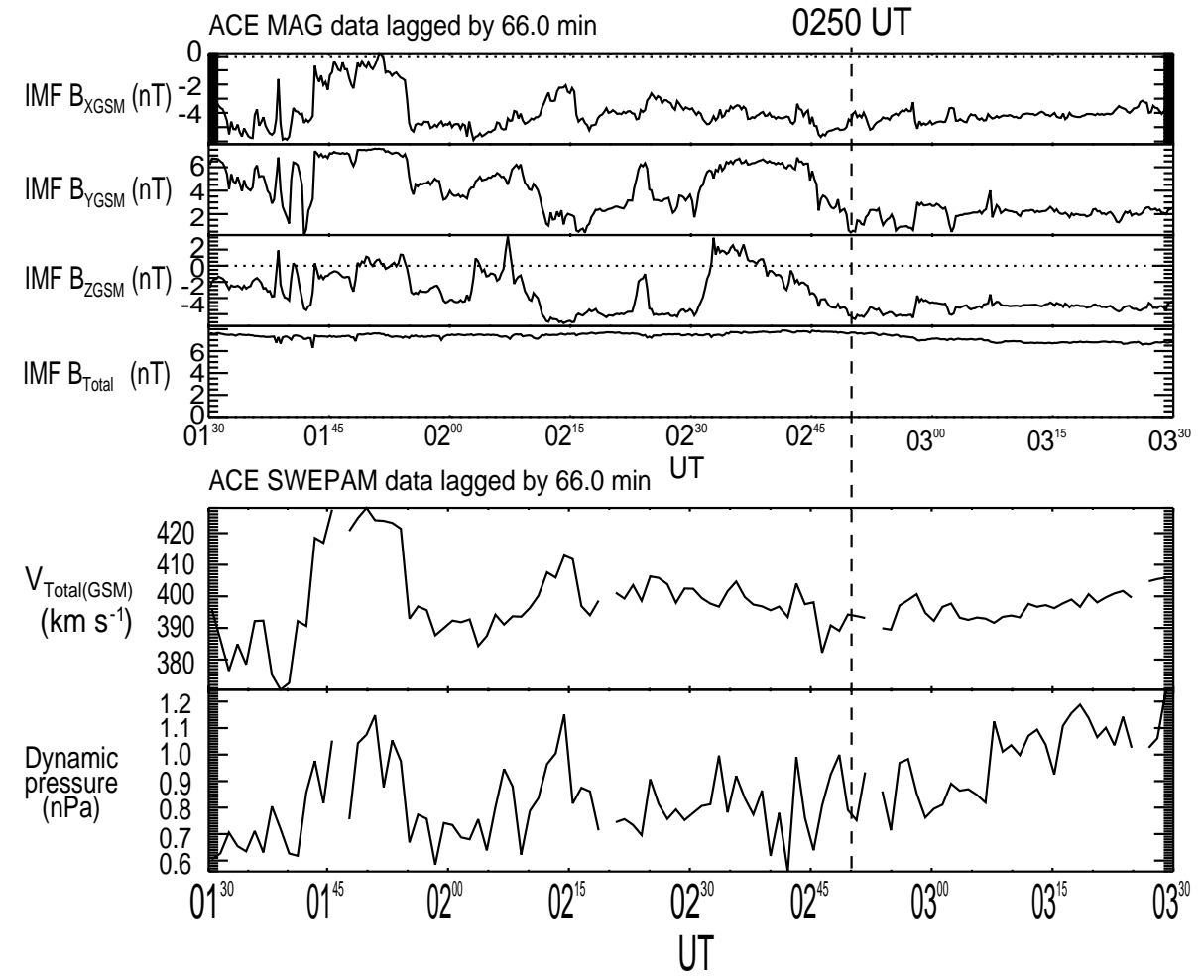

Fig. 4. ACE MAG and SWEPAM data for 5 October 2002, from 01:30 to 03:30 UT, lagged by 66 min. Top panel depicts MAG data: $B_{x}$, $B_{y}, B_{z}$ components of magnetic field and the total magnetic field, in GSM coordinates. Bottom panel depicts SWEPAM data: total velocity and dynamic pressure. 


\section{GOES $8 \mathrm{MFI}$}

5 Oct 2002

0250UT 0256UT

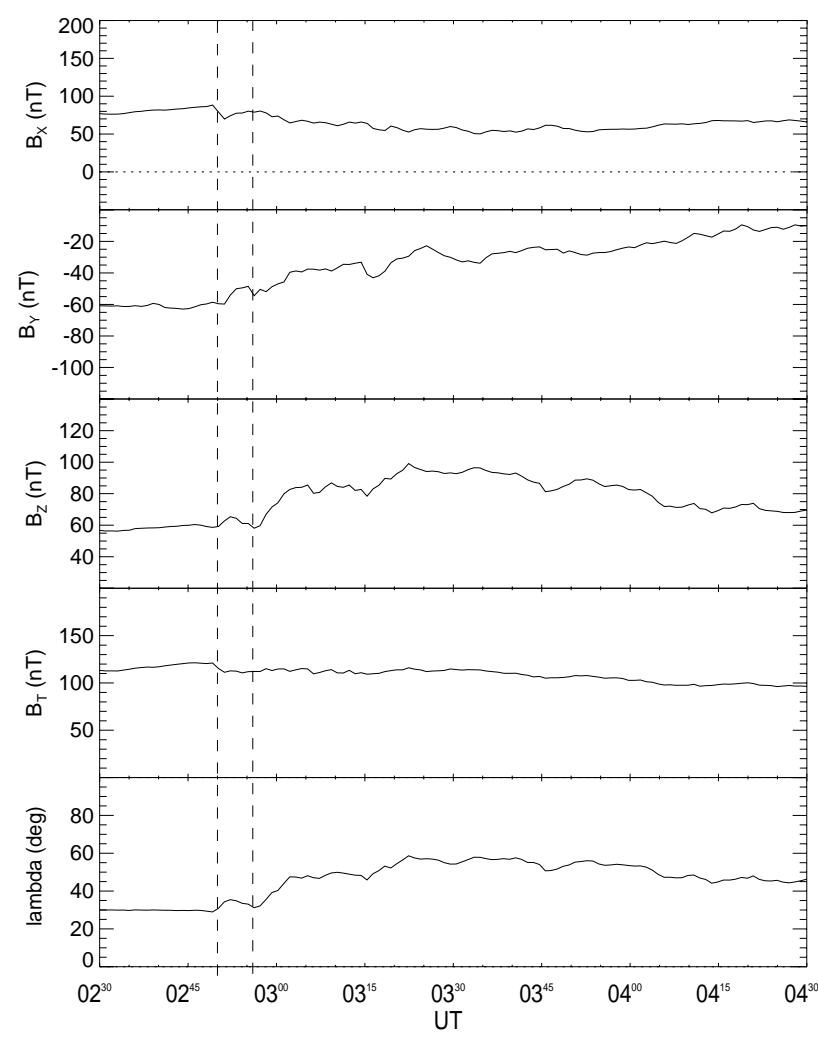

Fig. 5. GOES 8 magnetometer data for 5 October 2002, from 02:30 to 04:30 UT. $B_{x}, B_{y}, B_{z}$ components of magnetic field, total magnetic field, and lambda, where $\tan \lambda=B_{z} / \sqrt{ }\left(B_{x}^{2}+B_{y}^{2}\right)$, are shown.

over the period of interest. At substorm onset, no strong flows were detected in the pre-midnight sector (see Fig. 3a). However, intensification of ionospheric flow occurred in the midnight sector to $\sim 800 \mathrm{~ms}^{-1}$ from 03:14 UT (24 min after onset; Fig. 3b), and to $\sim 1000 \mathrm{~ms}^{-1}$ from 03:20 UT (30 min after onset; Fig. 3c).

The IMF conditions for this event are shown in Fig. 4. These are data from the MAG and SWEPAM instruments on the ACE spacecraft for 5 October 2002, from 01:30 to 03:30 UT. They are lagged by $66 \mathrm{~min}$ to take into account the time between the solar wind being detected at the spacecraft and it reaching the Earth's magnetopause. This lag is found using the technique of Khan and Cowley (1999). The IMF conditions around onset time were generally steady, with $B_{z}$ negative for around $45 \mathrm{~min}$ prior to onset (apart from a small northward excursion around 15 min prior to onset). After onset the IMF conditions remained steady with $B_{z}$ negative. The solar wind velocity was $\sim 400 \mathrm{kms}^{-1}$ for the interval, and the dynamic pressure underwent a graduated increase from $\sim 0.9 \mathrm{nPa}$ to $\sim 1.1 \mathrm{nPa}$ over $\sim 40 \mathrm{~min}$. It is worth noting that the data show no evidence for substorm triggering.

\subsection{Near-Earth instruments}

Figure 5 shows magnetometer data from the GOES 8 spacecraft for 5 October 2002, from 02:30 to 04:30 UT. In GSM, this spacecraft was located 5.5 $R_{E}$ downtail, $3.4 R_{E}$ from midnight in the pre-midnight sector and within $0.5 R_{E}$ of the GSM equatorial plane in the 22:00 MLT sector. The satellite is located north of the magnetic equator. A slight increase in the latitude angle of the field, $\lambda$ (where tan $\left.\lambda=B_{z} / \sqrt{ }\left(B_{x}^{2}+B_{y}^{2}\right)\right)$, is observed at 02:50 UT and is followed by a stronger increase at 02:56 UT, indicating dipolarization of the magnetic field at $6.6 R_{E}$ downtail. This is the signature of expansion phase onset at this location in the magnetosphere.

Particle data from the Synchronous Orbit Particle Analyzer instruments (SOPA; Belian et al., 1992) on the LANL01A (located in 04:00 MLT sector at 03:00 UT), -02A (08:00 MLT at 03:00 UT), -97A (10:00 MLT at 03:00 UT) and 1991-080 (16:00 MLT at 03:00 UT) spacecraft are shown in Figs. 6 (50-315 keV electrons) and 7 (50-400 keV protons) for 5 October 2002, from 00:00 to 06:00 UT. The spacecraft located closest to the magnetotail at substorm expansion phase onset is therefore LANL-01A. The electron data show a plasma injection at this spacecraft at 02:51 UT, with dispersed injections resulting from this event detected at other spacecraft at later times, most notably at the spacecraft located at 16:00 MLT (1991-080). The proton data show an increase in the dispersed injection at all spacecraft, occurring earliest at 02:55 UT at the spacecraft located at 16:00 MLT (1991-080).

\subsection{Cluster data overview}

\subsubsection{Cluster particle data}

The ion data from the CIS instrument on Cluster 1, 3 and 4 are shown in Fig. 8 for 5 October 2002, from 02:30 to 04:30 UT. Note that the CIS instrument on Cluster 2 was not operational. The plots show the low energy $(0.02 \mathrm{eV}$ to $30 \mathrm{keV}$ ) ion density, $V_{x}$ and $V_{y}$ velocity components (GSM coordinates $)$ and plasma beta $\left(2 \mu_{0} \mathrm{nkT}_{\perp} / \boldsymbol{B}^{2}\right.$, calculated from CIS and FGM data). Figure 9 shows low energy electron $(0.7 \mathrm{eV}$ to $30 \mathrm{keV})$ flux data from the four PEACE instruments, and Fig. 10 shows high energy electron flux data (20 to $400 \mathrm{keV}$ ) from the four RAPID-IES instruments.

The CIS instrument detected an ion density of $\sim 0.1 \mathrm{~cm}^{-3}$ before the substorm expansion phase onset at 02:50 UT, indicating that the Cluster spacecraft were located in the plasma sheet. The PEACE and RAPID-IES data corroborate this: the PEACE instrument detected a differential flux of $\sim 0.5$ counts s$~_{-1} \mathrm{~cm}^{-2} \mathrm{sr}^{-1} \mathrm{keV}^{-1}$ in the 1 to $10 \mathrm{keV}$ energy range, while the RAPID-IES instrument detected a differential flux of $\sim 2.7$ counts s${ }^{-1} \mathrm{~cm}^{-2} \mathrm{sr}^{-1} \mathrm{keV}^{-1}$ in the 40 to $400-\mathrm{keV}$ range. At 02:57 UT they entered the plasma sheet boundary layer, as the density began to decrease and fast Earthward-directed beams (composed primarily of protons) in the $V_{x}$ component of velocity were detected by the 


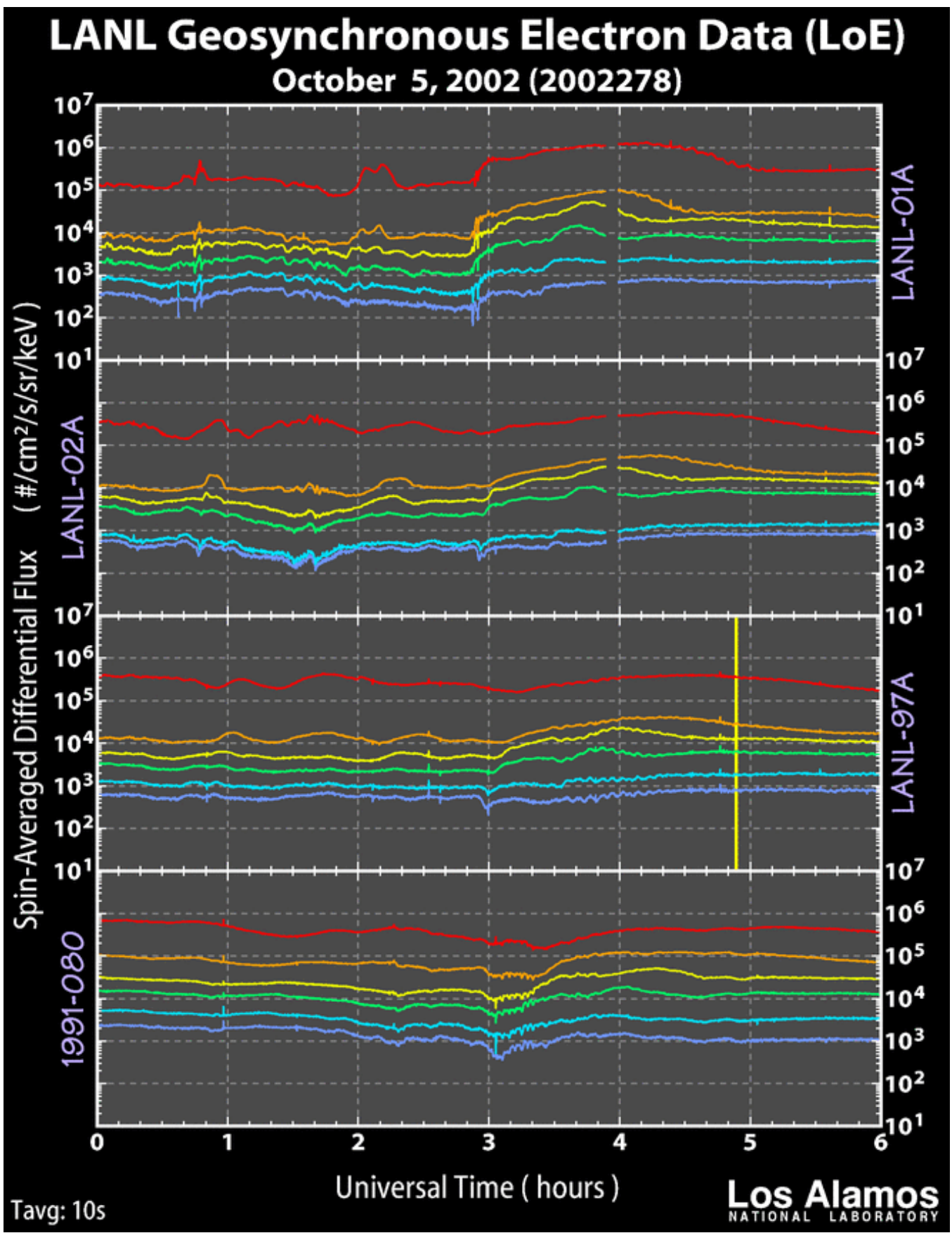

Fig. 6. LANL low energy electron data for 5 October 2002, from 00:00 to 06:00 UT.

CIS instruments. Such beams are the signature of the plasma sheet boundary layer (PSBL, e.g. Baumjohann et al., 1988). These beams became tailward-directed from 03:08 UT until 03:14 UT, but had plasma characteristics similar to the Earthward-directed beams. The PEACE data show that the spacecraft did not exit swiftly from the PSBL, but remained in it for around $15 \mathrm{~min}$ before entering the lobe at 03:14 UT. Cluster 3, which was located closest to the equatorial plane, detected the smallest decrease in density and the smallest plasma beams. This is consistent with Cluster 3 being further into the plasma sheet than the other spacecraft. At 03:30 UT the plasma instruments on the Cluster spacecraft detected plasma densities close to those before onset, indicating that they re-entered the plasma sheet at that time. This was accompanied by further PSBL beam signatures detected by the CIS instrument, directed mainly Earthward.

The plasma beta plots for the three spacecraft clearly depict the spacecraft as initially in the plasma sheet, when plasma beta is close to 1 . Plasma beta decreases at all spacecraft at 02:57 UT when the spacecraft enter the PSBL, 


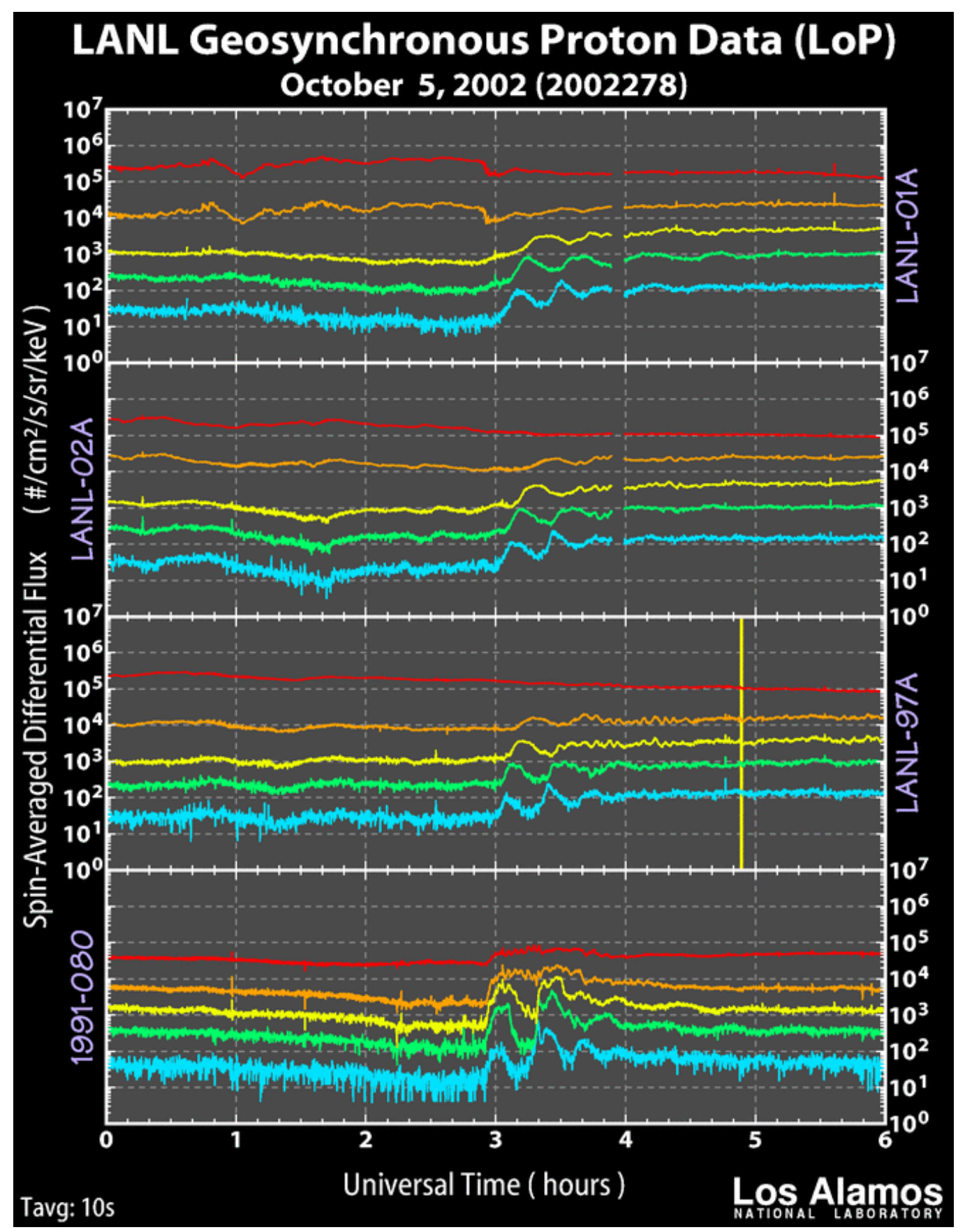

Fig. 7. LANL low energy proton data for 5 October 2002, from 00:00 to 06:00 UT.

fluctuating between $\sim 10^{-4}$ and 1 at spacecraft 1 and 4 and between $\sim 10^{-2}$ and 1 at spacecraft 2 , then show a clear transition to the lobe at 03:14 UT when plasma beta is less than $10^{-2}$ at all spacecraft. There is another clear transition at 03:30 UT when the spacecraft re-enter the plasma sheet, with plasma beta recovering to $\sim 1$ at all spacecraft.

\subsubsection{Cluster Magnetic Field Data}

The Cluster FGM data are shown in panels 1 to 4 of Fig. 11a, and in more detail for the 02:40 to 03:10 UT interval in the top four panels of Fig. 11b. Starting 02:51 UT (1 min after onset), there was a decrease in the $\mathrm{x}$ component of the magnetic field from $\sim 33 \mathrm{nT}$ to $\sim 26 \mathrm{nT}$ over a 4-min period. Over this same period, the $\mathrm{z}$ component of the magnetic field also decreased, from $\sim 0 \mathrm{nT}$ to $\sim-6 \mathrm{nT}$, and then recovered to $\sim 0 \mathrm{nT}$. All spacecraft detected the decrease at virtually the same time with detailed analysis revealing that Cluster 4 , located farthest downtail, detected the negative turning of $B_{z}$ last; the recovery was also detected slightly earlier by Cluster 1 than by Cluster 4 . Usually, dipolarization of the 
Cluster CIS

5th October 2002

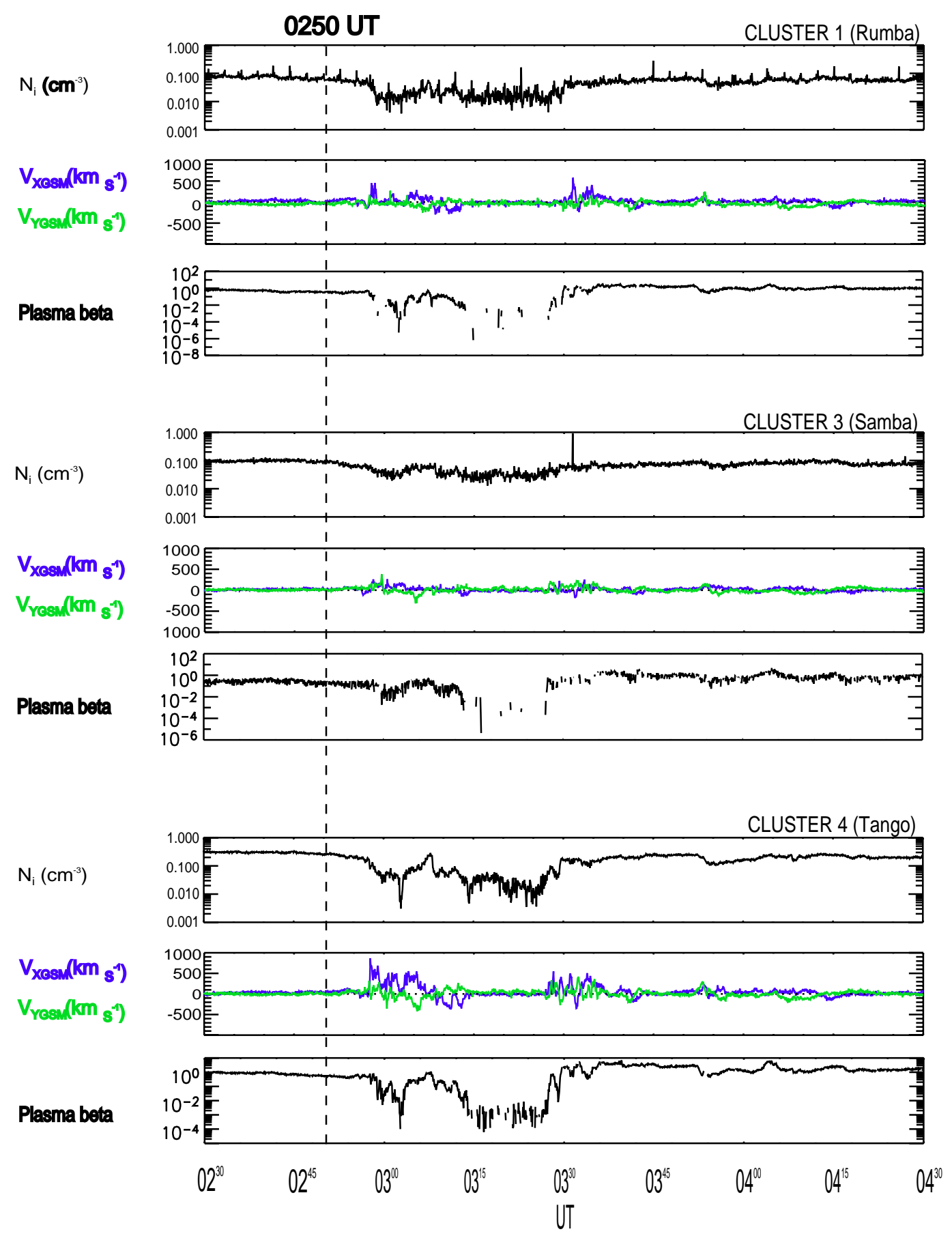

Fig. 8. Cluster CIS ion data from spacecraft 1, 3 and 4 for 5 October 2002, from 02:30 to 04:30 UT; density, x and y velocity components (GSM coordinates) and plasma beta are shown for each spacecraft.

magnetic field at substorm expansion phase onset is characterized by a decrease of the $\mathrm{x}$ component of magnetic field, accompanied by a positive increase in the $\mathrm{z}$ component of magnetic field (e.g. Baumjohann et al., 1999). Therefore the signature detected in this case was not associated with dipolarization.
The current densities calculated from the magnetic field are shown in panels 5 to 7 of Fig. 11a. These are calculated from FGM data from all four spacecraft, with an indication of the accuracy of the calculation given by the divergence of $\boldsymbol{B}$ (panel 8). When the divergence of $\boldsymbol{B}$ is close to zero, the values calculated for the current densities are reliable. Prior 


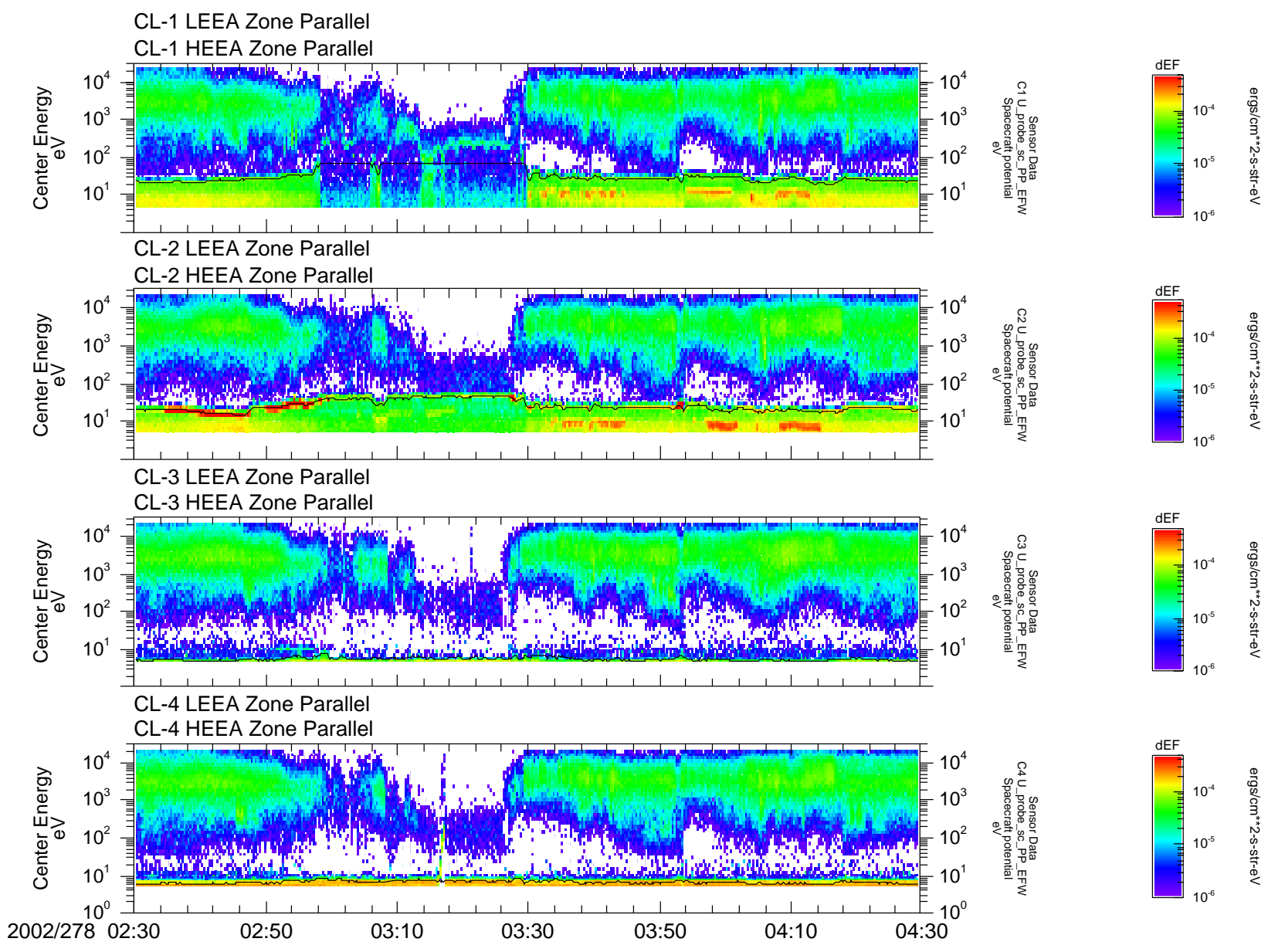

Fig. 9. Cluster PEACE electron energy data from all spacecraft for 5 October 2002, from 02:30 to 04:30 UT.

to onset a current density of $\sim 0.8 \times 10^{-9} \mathrm{Am}^{-2}$ was detected in the $y$ direction, indicative of the cross-tail current at the location of the Cluster spacecraft. This current was mainly due to a difference of the $\mathrm{x}$ component of the magnetic field in the $\mathrm{z}$ direction. The spacecraft detected a total magnetic field of $\sim 30 \mathrm{nT}$ prior to onset, indicating a change in $B_{x}$ of $\sim 60 \mathrm{nT}$ across the plasma sheet inside Cluster. Typically, the current sheet thickness would be around $5 R_{E}$. This implies a total current of $\sim 60 \mathrm{nT} /\left(\mu_{0} \times 5 R_{E}\right)$, or $\sim 2 \times 10^{-9} \mathrm{Am}^{-2}$. This is of the order of twice the value deduced from the FGM data, and is consistent with a spacecraft location away from the centre of the plasma sheet (where the current density is reduced). A few minutes prior to onset this $J_{y}$ current density is lost, but the total magnetic field remains the same, indicating that the total current within the plasma sheet has remained the same.

When the spacecraft crossed into the plasma sheet boundary layer from the plasma sheet at 02:57 UT, predominantly Earthward-directed $J_{x}$ current densities were detected by the spacecraft to a peak value of $\sim 2.3 \times 10^{-9} \mathrm{Am}^{-2}$. At 03:30 UT, the spacecraft crossed the plasma sheet boundary layer from the lobe back into the plasma sheet, and this time mainly tailward-directed $J_{x}$ current densities were detected, to a peak value of $\sim-2.7 \times 10^{-9} \mathrm{Am}^{-2}$. Examination of the magnetic field data shows that these currents were associated mainly with $B_{y}$ varying in the $\mathrm{z}$ direction, rather than $B_{z}$ varying in the y direction.

\section{Discussion}

The substorm expansion phase onset timing for this substorm is taken as 02:50 UT. This is from the earliest Pi2 pulsation detection at the PIN and ISL magnetometer stations of the CANOPUS network. It has been deduced that the westward electrojet was located poleward of the ISL station and located equatorward of the NAQ Greenland station after onset. Combining these observations constrains the substorm electrojet to the region shown by the shaded area in Fig. 12. This region was in the pre-midnight sector during this interval of the substorm and extended over $4 \mathrm{~h}$ of magnetic local time.

Prior to substorm expansion phase onset the current densities calculated from the magnetic field measurements at the Cluster spacecraft indicated a value of $J_{y}$ current around half the probable average in that region. This small value of cross-tail current indicates that the spacecraft were located away from the centre of the plasma sheet. $J_{y}$ then returned 


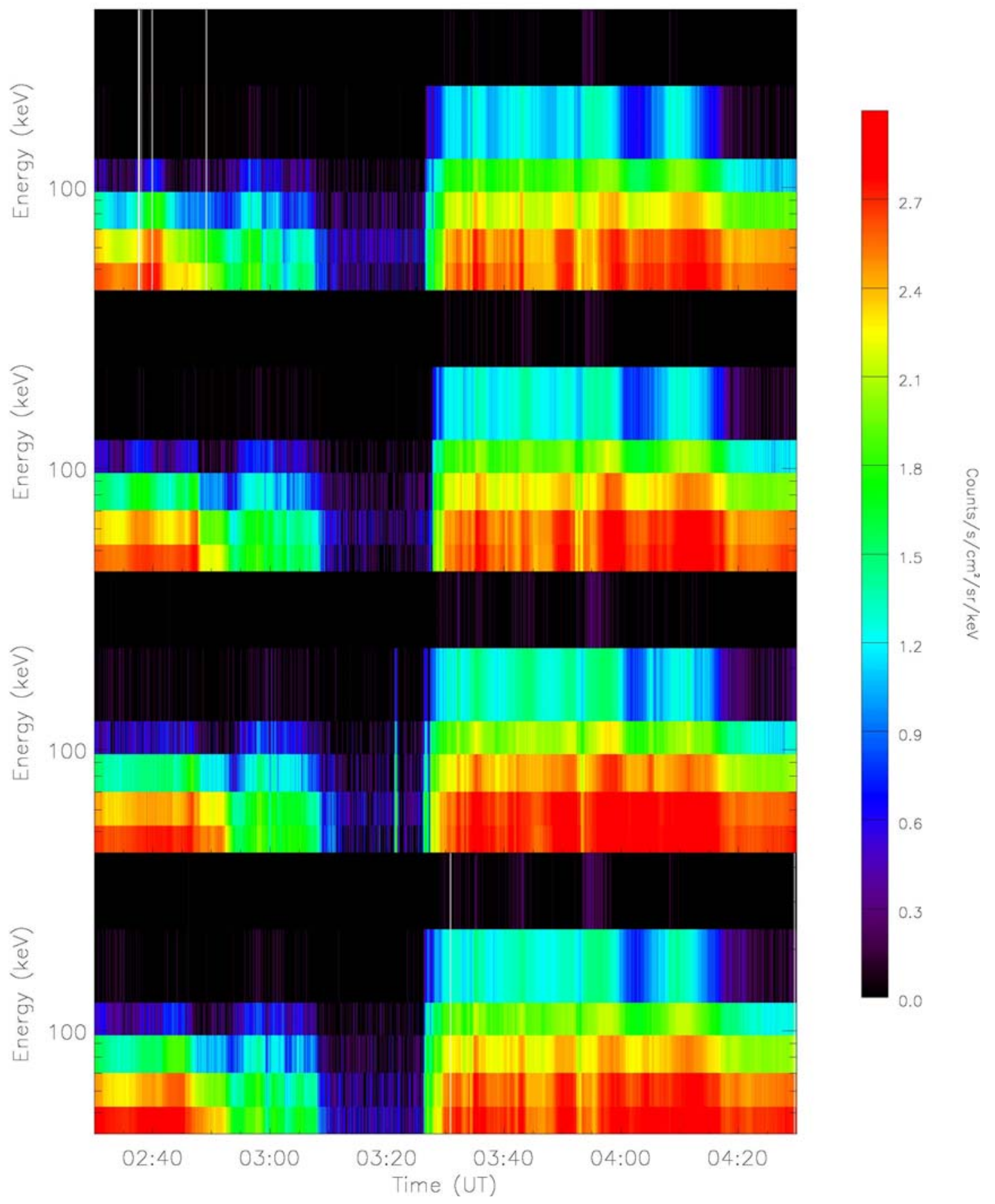

Fig. 10. Cluster RAPID-IES electron energy data for 5 October 2002, from 02:30 to 04:30 UT.

to $\sim$ zero a few minutes before onset while the total magnetic field remained constant. This is consistent with the rapid thinning of the current sheet within the plasma sheet during the growth phase of the substorm, leaving the spacecraft located above this thinned current sheet.

At 02:51 UT, 1 min after substorm expansion phase onset, the Cluster spacecraft detected a signature not consistent with substorm expansion phase onset in the magnetic field data prior to exiting the plasma sheet to the plasma sheet boundary layer. At onset one would expect to see a classic dipolarization signature for a spacecraft located Earthward of a near-Earth neutral line, with a decrease in the $\mathrm{x}$ component of magnetic field and increase in the $\mathrm{z}$ component. Here $B_{x}$ increased very slightly then strongly decreased, and $B_{z}$ decreased, becoming strongly negative for $7 \mathrm{~min}$. $B_{x}$ remained reduced when the spacecraft entered the plasma sheet boundary layer, but $B_{z}$ recovered to its original value of $\sim 1 \mathrm{nT}$. This signature is consistent with the formation of a reconnection site Earthward of the spacecraft, creating a plasmoid whose centre was tailward of the spacecraft which then formed a TCR, as illustrated in Fig. 13a. Thus only fields with a negative $\mathrm{z}$ component were observed as 
CLUSTER Fluxgate Magnetometer (FGM)
05 October 2002

CLUSTER 1 (Rumba)

CLUSTER 2 (Salsa)

CLUSTER 4 (Tango)

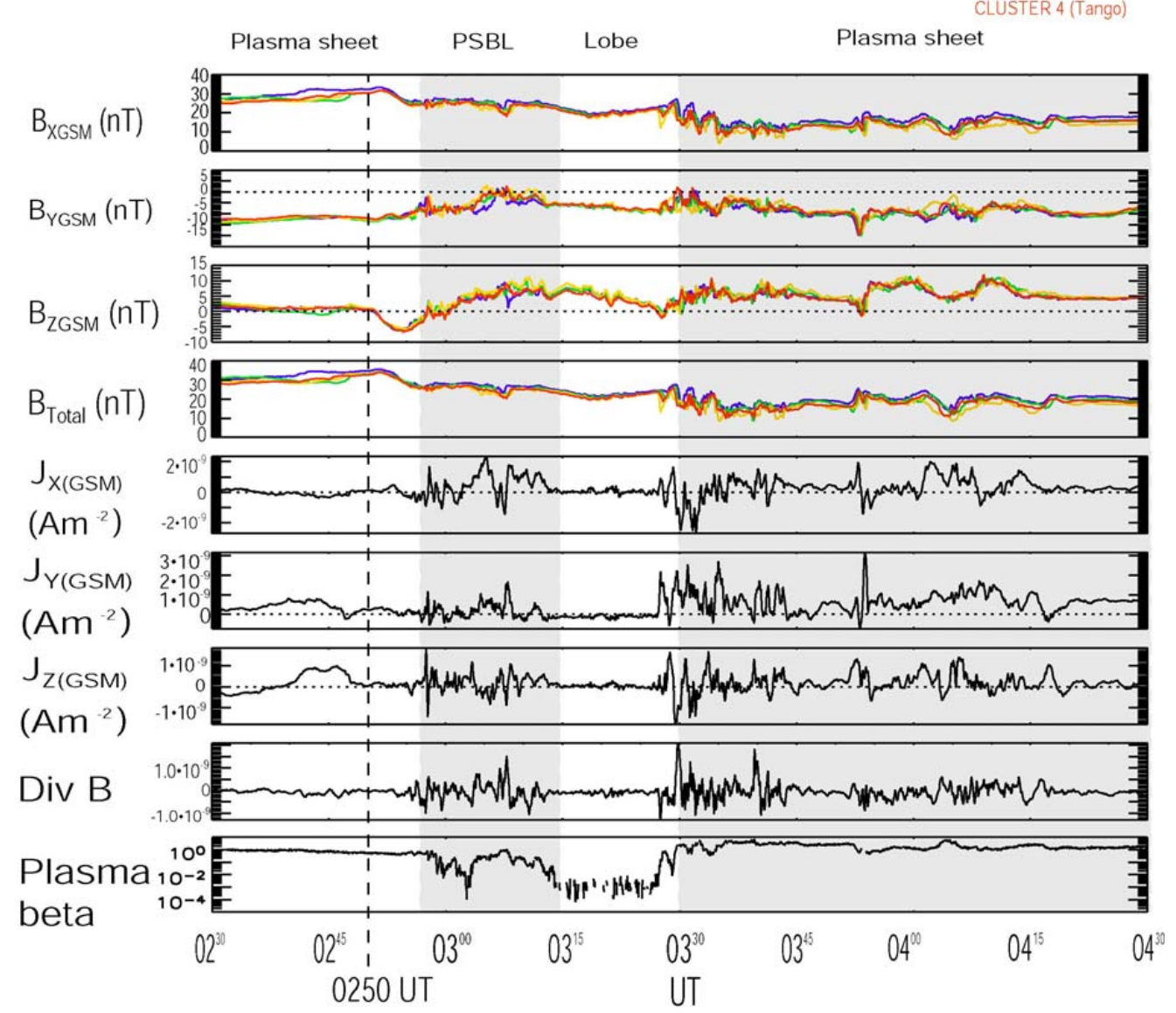

Fig. 11. (a) Cluster FGM data for 5 October 2002, from 02:30 to 04:30 UT. $B_{x}, B_{y}, B_{z}$ components of the magnetic field (GSM coordinates), the total magnetic field, $J_{x}, J_{y}, J_{z}$ components of the current (also GSM coordinates), div $\boldsymbol{B}$ and plasma beta are shown, with shaded areas representing regions of magnetosphere;

the TCR formed and then departed tailward. The tailward motion is corroborated by the order in which the spacecraft detected the TCR: the spacecraft farthest downtail, Cluster 4, detected the TCR last. The formation of this plasmoid resulting in a TCR under the spacecraft places the spacecraft tailward of a near-Earth neutral line, and positive $B_{x}$ confirms that the spacecraft were above the plasma sheet centre, in the PSBL. Analysis of the timings for the peak in $B_{x}$, the negative turning of $B_{z}$ and the peak in $B_{\text {total }}$ revealed that the TCR was travelling at $\sim 200 \mathrm{kms}^{-1}$. This is around one quarter the values described in Slavin et al. (2005), but may be accounted for by the fact that the TCR was still in its early stages of formation. Immediately after the plasmoid departed downtail and $B_{z}$ returned to small positive values, the spacecraft all detected a decrease in plasma densities and a sustained increase in plasma velocities for up to $10 \mathrm{~min}$ at Cluster 4. The Cluster 3 spacecraft, located closest to the equatorial plane, detected the weakest beams and smallest decrease in plasma density. This began at 02:57 UT, and indicates that the spacecraft entered the PSBL at that time; their location is illustrated in Fig. 13b. There was therefore a significant time delay $(6 \mathrm{~min})$ between the measurement of a negative $B_{z}$ and the subsequent detection of Earthward flows which is accounted for by this scenario. Figure $13 \mathrm{c}$ illustrates the departure of the plasmoid downtail. From 03:08 UT the beams were tailward and detected mainly by Cluster 1 and 4, indicating that the beams were located only on the outer edge of the plasma sheet and not further into the plasma sheet where the Cluster 3 spacecraft was located. The tailward beams indicate that the spacecraft may have detected PSBL particles that were mirrored at the Earth and returned to the location of the spacecraft during time-dependent behaviour of the plasma sheet, but further study is required to determine whether this is the case. From here the spacecraft exited to the lobe. At 03:30 UT, the spacecraft re-entered the plasma sheet from the lobe, again crossing the PSBL, and detected increased densities and high-speed Earthward plasma beams. Taguchi et al. (1998) 


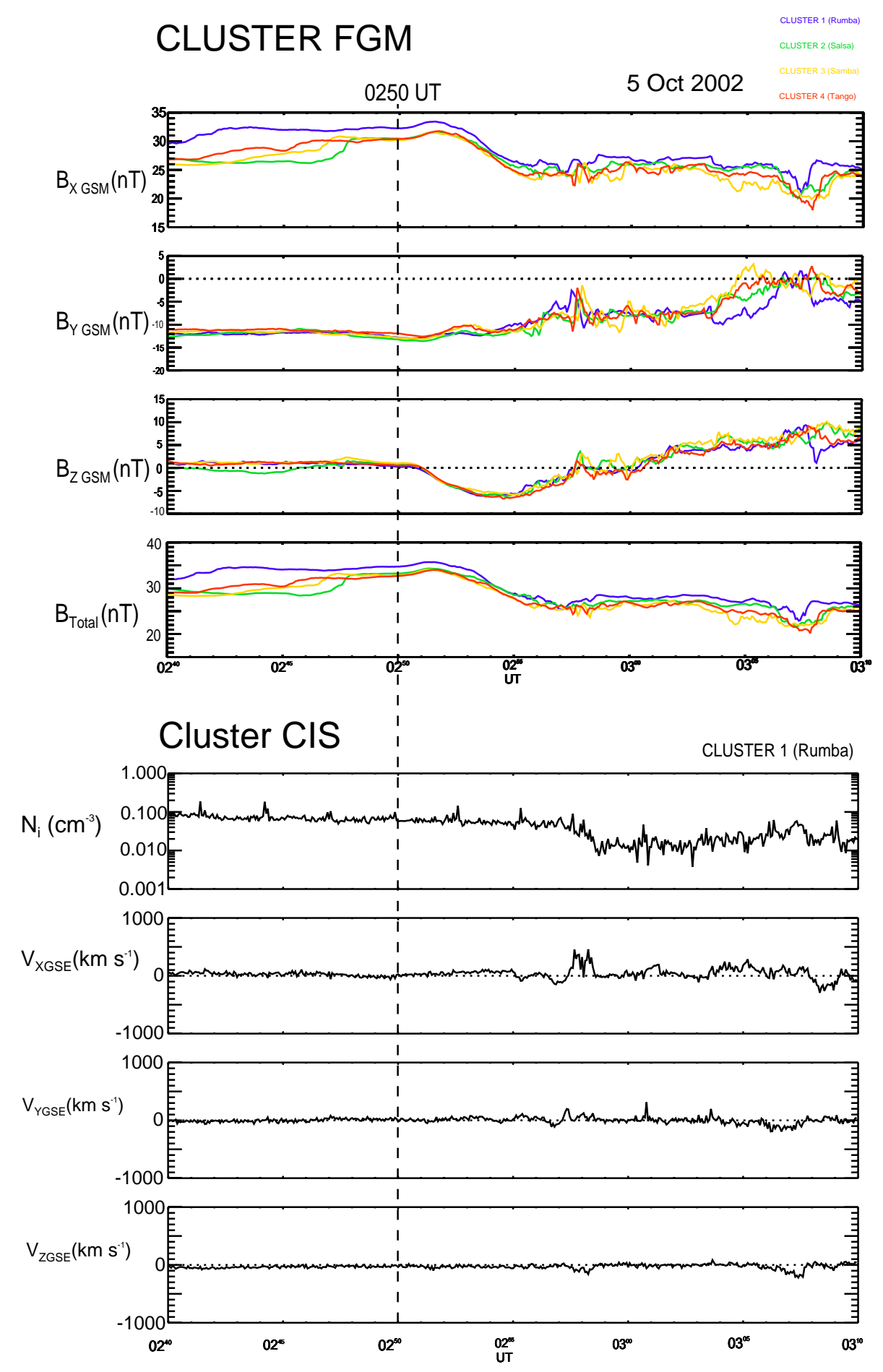

Fig. 11. (b) zoomed view for the 02:40 to 03:10 UT interval: $B_{x}, B_{y}, B_{z}$ and $B_{\text {total }}$ Cluster FGM data from the four spacecraft and density, $V_{x}, V_{y}$ and $V_{z}$ CIS data from Cluster 1.

examined the midtail lobe TCRs relative to onset during substorm events and interpreted "the flat $B_{Z}$ phase preceding the south tilting interval" in the same way as for this event: "being due to the close proximity to the growing plasmoid bulge just prior to plasmoid ejection down the tail".
At around 03:05 UT a large $J_{x}$ current density, predominantly in the Earthward direction, was detected at the Cluster spacecraft as they left the plasma sheet. A predominantly tailward $J_{x}$ current density was detected upon re-entry to the plasma sheet at 03:30 UT. These currents are due to a difference of the y component of the magnetic field in the 


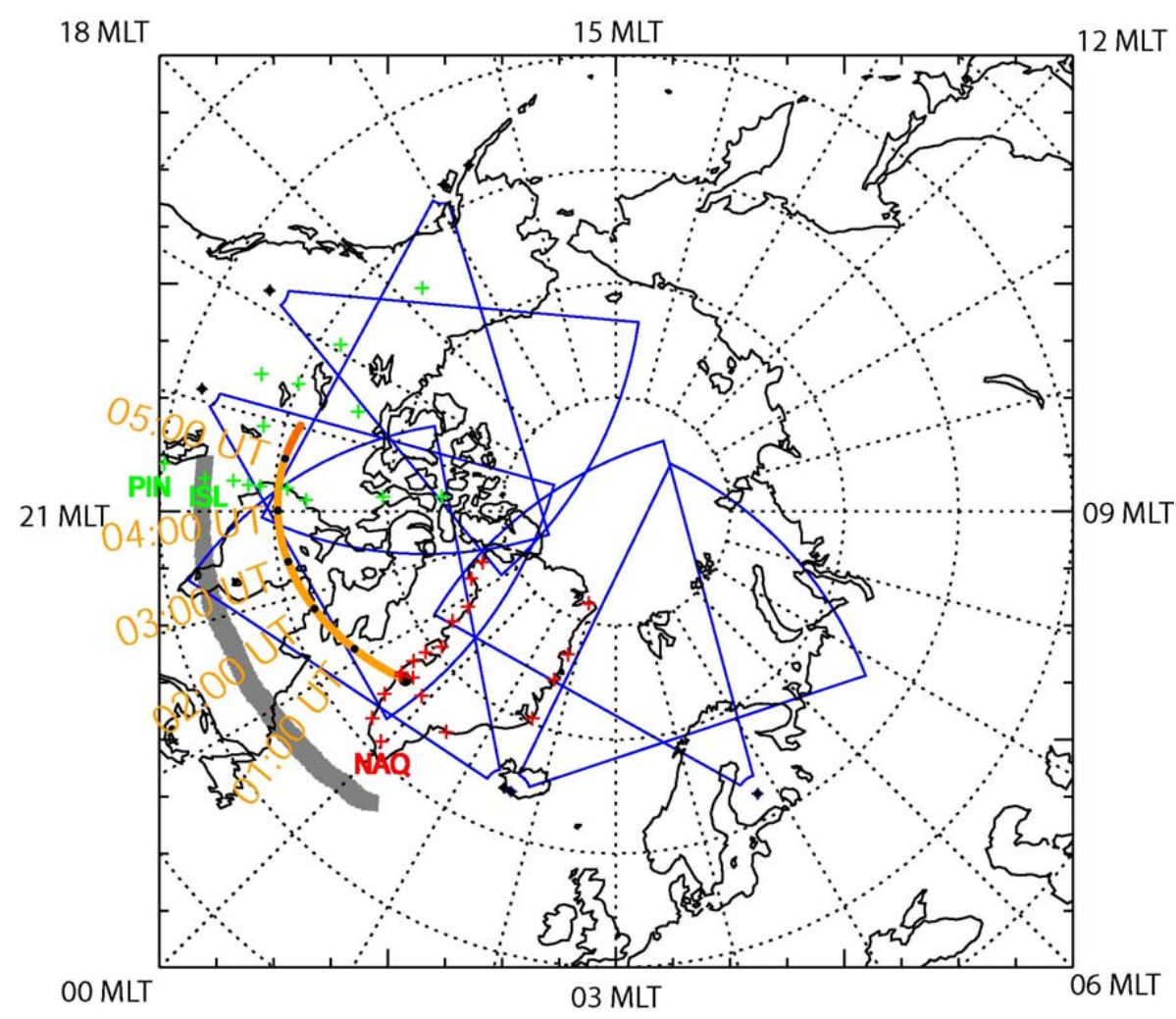

Fig. 12. Northern Hemisphere at 03:00 UT on 5 October 2002 in geographic coordinates; shaded area indicates region of substorm electrojet during substorm.
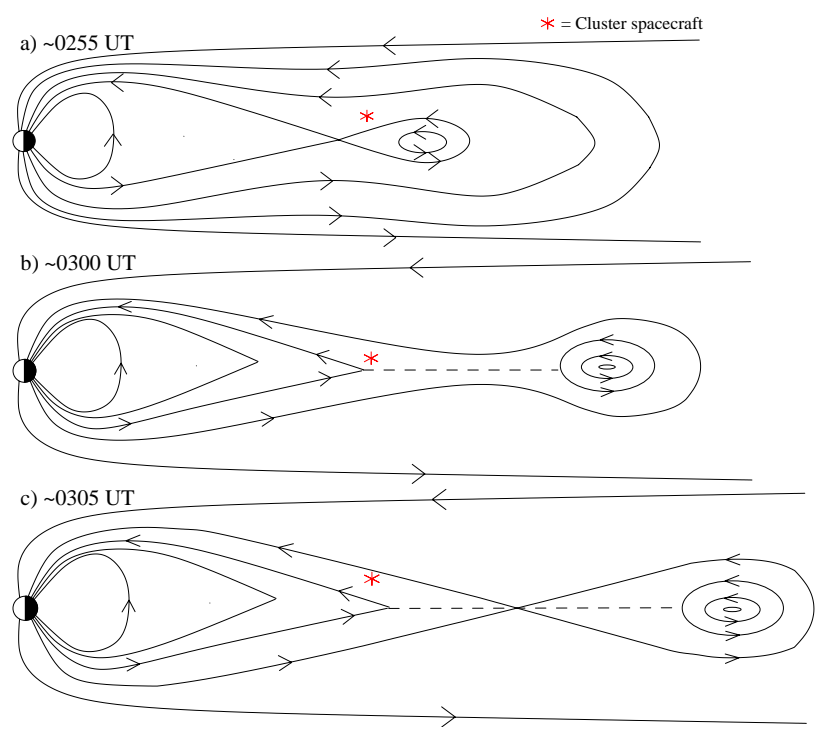

Fig. 13. (a) location of spacecraft within magnetopause around 02:55 UT; (b) location of spacecraft around 03:00 UT; (c) location of spacecraft around 03:05 UT. $z$ direction, rather than being due to the difference of the $\mathrm{z}$ component in the $\mathrm{y}$ direction. This suggests that these Earthward- and tailward- directed currents are flowing in a sheet at the boundary of the plasma sheet, in the interface between open and closed field lines. Such sheets of current, having the sense of "Region 1" field-aligned currents, have been observed in substorm simulations (e.g. Birn and Hesse, 1996), with an explanation which is illustrated in Fig. 14.

Figure 14a shows the $x-y$ plane of the magnetosphere, with open field lines above the plasma sheet depicted by dashed blue lines. The dashed red line in the y direction represents the reconnection line which occupies the central part of the tail, shown symmetric about midnight for the simplest case. The dashed red lines with arrows depict plasma streamlines away from the reconnection line, representing the paths followed by the ends of the newly-reconnected closed field lines. These imply that a $V_{y}$ velocity component should be present in the downstream flow, carrying the newly-closed field lines away from the reconnection region in the midnight sector towards both dawn and dusk, as required to distribute the newly-reconnected flux broadly through the closed field region. The dawnward and duskward motion causes the reconnected field lines to twist in direction in the plasma sheet as shown by the black solid lines, the twist in the Northern Hemisphere being towards dawn on the dusk side, and 
towards dusk on the dawn side, and vice versa in the Southern Hemisphere.

The consequent shear in $B_{y}$ at the surface of the plasma sheet is associated with a field-aligned current directed towards and away from the Earth which has the sense of the "Region 1" current, i.e. Earthward at dawn, and tailward at dusk. This is shown in Fig. 14b, where we show a cut through the $\mathrm{y}-\mathrm{z}$ plane in a region just Earthward of the reconnection line. The pre-existing plasma sheet is located on either side of the lozenge-shaped portion of the recentlyreconnected plasma sheet, which is enhanced as a result of the increased flux of closed field lines within it. A projection of these newly-closed field lines onto this cross-section is depicted by the black lines; the shear in the $B_{y}$ component between plasma sheet and lobe can clearly be seen. This results in the current flow along the surface of the plasma sheet, which is depicted by circled blue crosses (current into the page) and dots (current out of the page). The current system is closed in the ionosphere and on the magnetopause.

At 03:05 UT, the Cluster spacecraft were located in the northern boundary of the plasma sheet ( $B_{x}$ is positive) and detected an Earthward current, which places them in the northern, dawnward portion of the scenario presented above. However, the spacecraft were actually located $8 R_{E}$ from midnight in the pre-midnight sector, from which we conclude that the reconnection site and consequent current system were skewed to the pre-midnight sector at this time. Previous observations show that substorm onsets are often located in the pre-midnight sector (e.g. Nagai et al., 1998). The $V_{y}$ velocities observed by the CIS instrument were indeed mainly negative (i.e. dawnward) during this interval, as then expected (see Fig. 8). Following this, the spacecraft exit to the lobe. Upon re-entry at 03:30 UT, they detect a tailward current in the lobe-plasma sheet boundary, again $8 R_{E}$ from midnight. This then places the spacecraft in the northern, duskward portion of the reconnection structure, from which we conclude that the reconnection region and current system had become more centrally-located in the tail by this time, as may be expected. The sense of the $V_{y}$ flow measured by CIS had also changed to become small but mainly duskward directed.

The question of which substorm onset mechanism is responsible for this substorm event is one that is difficult to resolve. The substorm onset was taken as 02:50 UT, the time at which Pi2 pulsations were detected at the PIN magnetometer station located at 21 MLT and the development of a westward electrojet. The westward electrojet subsequently developed at NAQ near midnight a few minutes later. The Pi2 pulsations were simultaneous with a small dipolarisation at the location of the GOES 8 spacecraft in the 22:00 MLT sector in geostationary orbit, which was followed $5 \mathrm{~min}$ later by a larger dipolarization. Just one minute after onset at 02:51 UT, the Cluster spacecraft detected the formation of a TCR $15 R_{E}$ downtail, in the pre-midnight sector. At the same time there was an electron injection detected by the LANL-01A spacecraft, in the 04:00 MLT sector in geostationary orbit. These signatures were detected at very widely spaced locations in
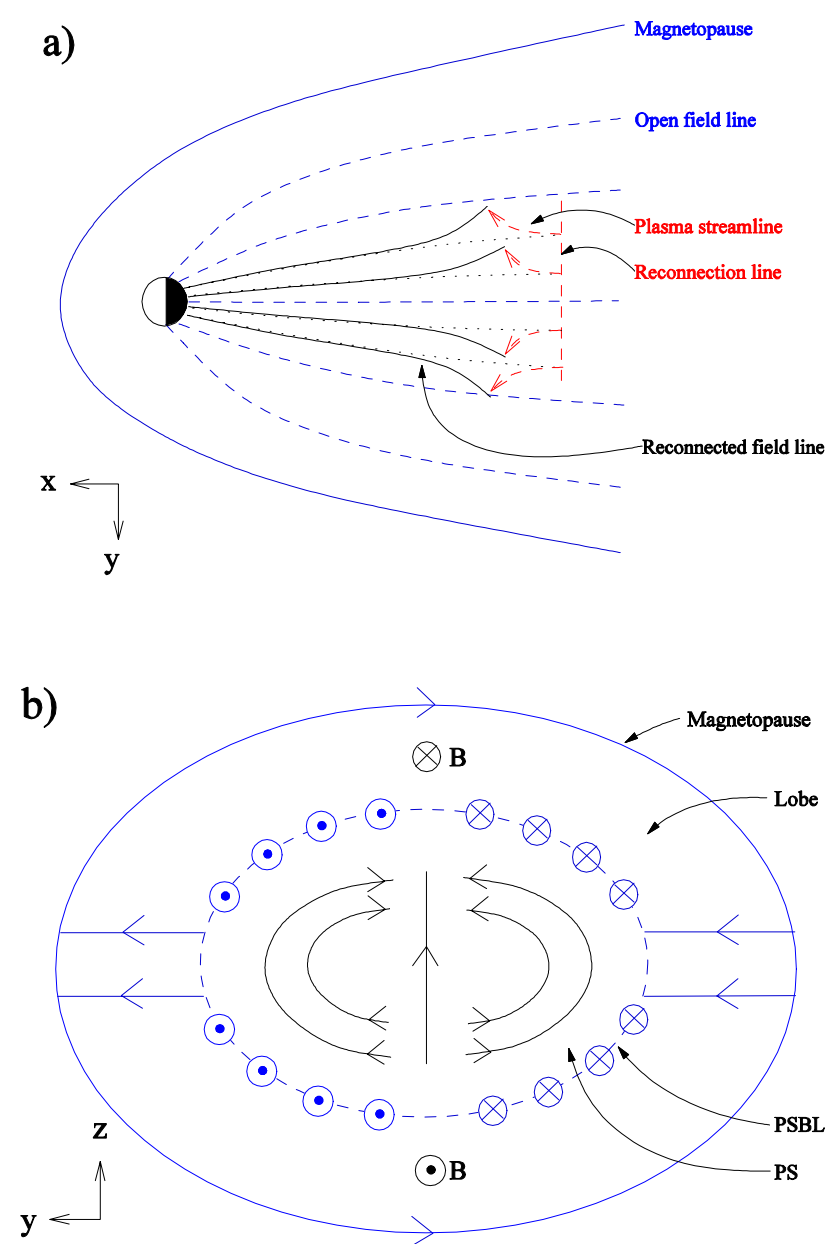

Fig. 14. (a) cut through $x-y$ plane of magnetosphere; (b) cut through $\mathrm{y}-\mathrm{z}$ plane of magnetosphere.

the magnetotail, and since they all occurred within just one minute of each other it is not possible to distinguish the location of initial onset for this substorm. Furthermore, the large local time extent of this event suggests that this was the onset of the full expansion phase rather than a spatially localized pseudobreakup.

It is worth noting that there was a further intensification of this substorm at $\sim 03: 15$ UT detected by the ISL and PIN magnetometer stations. There was also a dipolarization at geostationary orbit detected by the GOES spacecraft at this time, and this is also related to the intensifications of ionospheric flow out of the polar cap depicted in the map potential plot for 03:14 to 03:16 UT (Fig. 3b). The Cluster spacecraft were located in the lobe at this time, and no dipolarization was detected at their location.

\section{Conclusions}

In this paper we have brought together several data sets which give a good overview of the conditions in the ionosphere, near-magnetosphere and magnetosphere during a 
substorm event on 5 October 2002. Despite not resolving the question of which mechanism was responsible for the substorm onset in this case, many other interesting findings have been presented. The magnetometer data set determines the time of onset as 02:50 UT; the time when Pi2 pulsations were first detected for this substorm. The location of the substorm electrojet is constrained using the magnetometer data, and LANL particle data infer the time at which plasma were injected at geosynchronous orbit. A small $J_{y}$ current detected before onset is lost a few minutes prior to onset. This indicates that the spacecraft detected the rapid thinning of the plasma sheet under the spacecraft prior to onset, i.e. during the growth phase. The negative $\mathrm{z}$ component of the magnetic field at substorm onset coupled with a large time delay before detection of Earthward flows is most easily explained by the formation of a tailward-moving plasmoid, producing a TCR at onset. The near-Earth neutral line therefore formed somewhere Earthward of the Cluster spacecraft at their location of $\sim 15 R_{E}$ downtail. Importantly, the Cluster spacecraft detected Region 1 currents during this interval flowing at the surface of the plasma sheet. In contrast to the usual SCW picture, these Region 1 currents were associated mainly with $B_{y}$ varying in the $\mathrm{z}$ direction, rather than $B_{z}$ varying in the y direction. Initially these currents were predominantly Earthward-directed as the spacecraft left the plasma sheet, then later were tailward-directed as the spacecraft re-entered the plasma sheet. These findings indicate that the Region 1 currents were initially skewed towards the pre-midnight sector, and later became more centrally-located about the midnight sector. This is consistent with previous findings that place substorm onset in the pre-midnight sector of the magnetotail.

Acknowledgements. The authors would like to thank the PIs for the SuperDARN radars from which data have been presented; the Cluster Principal Investigators for the FGM (A. Balogh), CIS (H. Rème), PEACE (A. Fazakerley) and RAPID (P. Daly) instruments; the ACE MAG and SWEPAM instrument teams and the ACE Science Center for providing the ACE MAG and SWEPAM data; the Canadian Space Agency (CSA) for supplying the CANOPUS magnetometer data; to M. G. Henderson for providing LANL data and to CDAWeb for providing the GOES data. Thanks also to D. S. Manning for assistance with figures. During this study J. A. Wild, G. Provan and A. Grocott were supported by PPARC grant PPA/G/O/2003/00013. N. C. Draper was funded by a University of Leicester postgraduate studentship.

Topical Editor T. Pulkkinen thanks J. Slavin and another referee for their help in evaluating this paper.

\section{References}

Baker, D. N., Pulkkinen, T. I., Angelopoulos, V., Baumjohann, W., and McPherron, R. L.: Neutral line model of substorms: Past results and present view, J. Geophys. Res., 101, 12 975-13010, 1996.

Balogh, A., Dunlop, M. W., Cowley, S. W. H., Southwood, D. J., Thomlinson, J. G., Glassmeier, K.-H., Musmann, G., Lühr, H., Buchert, S., Acuña, M. H., Fairfield, D. H., Slavin, J. A., Riedler,
W., Schwingenschuh, K., and Kivelson, M. G.: The Cluster magnetic fields investigation Space Sci. Rev., 79, 65-91, 1997.

Baumjohann, W., Paschmann, G., Sckopke, N., Cattell, C. A., and Carlson, C. W.: Average ion moments in the plasma sheet boundary layer, J. Geophys. Res., 93, 11 507-11 520, 1988.

Baumjohann, W., Hesse, M., Kokubun, S., Mukai, T., Nagai, T., and Petrukovich, A. A.: Substorm dipolarization and recovery, J. Geophys. Res., 104, 24 995-25 000, 1999.

Belian, R. D., Baker, D. N., Higbie, P. R., and Hones, E. W.: Highresolution energetic particle measurements at $6.6 R_{E}: 2$ highenergy proton drift echoes, J. Geophys. Res., 83, 4857-4862, 1978.

Belian, R. D., Gisler, G. R., Cayton, T., and Christensen, R.: High$\mathrm{Z}$ Energetic Particles at Geostationary Orbit During the Great Solar Proton Event Series of October 1989, J. Geophys. Res., 97, 16897-16906, 1992.

Birn, J. and Hesse, M.: Details of current disruption and diversion in simulations of magnetotail dynamics, J. Geophys. Res., 101, 15 345-15 358, 1996.

Cowley, S. W. H.: Magnetosphere-ionosphere interactions - a tutorial review, in: Magnetospheric Current Systems, edited by: Ohtani, S., Fujii, R., Hesse, M., and Lysak, R. L., Geophys. Monograph 118, AGU Publ., Washington, USA, 91-106, 2000.

Friis-Christensen, E., Kamide, Y., Richmond, A. D., and Matsushita, S.: Interplanetary magnetic field control of high-latitude electric fields and currents determined from Greenland magnetometer data, J. Geophys. Res., 90, 1325-1338, 1985.

Greenwald, R. A., Baker, K. B., Dudeny, J. R., Pinnock, M., Jones, T. B., Thomas, E. C., Villain, J.-P., Cerisier, J.-C., Senior, C., Hanuise, C., Hunsucker, R. D., Sofko, G., Koehler, J., Nielsen, E., Pellinen, R., Walker, A. D. M., Sato, N., and Yamagishi, H.: Darn/SuperDARN: a global view of the dynamics of highlatitude convection Space Sci. Rev., 71, 761-796, 1995.

Hones Jr., E. W., Baker, D. N., Bame, S. J., Fedman, W. C., Gosling, J. T., McComas, D. J., Zwickl, R. D., Slavin, J. A., Smith, E. J., and Tsurutani, B. T.: Structure of the magnetotail at $220 \mathrm{R}_{E}$ and its response to geomagnetic activity, Geophys. Res. Lett., 11, 57, 1984.

Ieda, A., Machida, S., Mukai, T., Saito, Y., Yamamoto, T., Nishida, A., Terasawa, T., and Kokubun, S.: Statistical analysis of the plasmoid evolution with Geotail observations, J. Geophys. Res., 103, 4453-4465, 1998.

Johnstone, A. D., Alsop, C., Burge, S., Carter, P. J., Coates, A. J., Coker, A. J., Fazakerley, A. N., Grande, M., Gowen, R. A., Gurgiolo, C., Hancock, B. K., Narheim, B., Preece, A., Sheather, P. H., Winningham, J. D., and Woodliffe, R. D.: Peace: A Plasma Electron and Current Experiment, Space Sci. Rev., 79, 351-398, 1997.

Khan, H. and Cowley, S. W. H.: Observations of the response time of high-latitude ionospheric convection to variations in the interplanetary magnetic field using EISCAT and IMP-8 data, Ann. Geophys., 17, 1306-1335, 1999,

SRef-ID: 1432-0576/ag/1999-17-1306.

Lui, A. T. Y.: Current disruption in the Earth's magnetosphere: Observations and models, J. Geophys. Res., 101, 13 067-13088, 1996.

McComas, D. J., Bame, S. J., Barker, P., Feldman, W. C., Philips, J. L., Riley, P., and Griffee, J. W.: Solar Wind Electron Proton Alpha Monitor (SWEPAM) for the Advanced Composition Explorer, Space Sci. Rev., 86, 563-612, 1998.

McPherron, R. L., Russell, C. T., and Aubry, M. P.: Satellite studies of magnetospheric substorms on August 15, 1968, 9, 
Phenomenological model for substorms J. Geophys. Res., 78, 3131-3149, 1973.

Nagai, T.: Observed magnetic substorm signatures at synchronous altitude, J. Geophys Res., 87, 4405-4417, 1982.

Nagai, T., Fujimoto, M., Saito, Y., Machida, S., Terasawa, T., Nakamura, R., Yamamoto, T., Mukai, T., Nishida, A., and Kokubun, S.: Structure and dynamics of magnetic reconnection for substorm onsets with Geotail observations, J. Geophys. Res., 103, 4419-4440, 1998.

Potemra, T. A.: Current systems in the Earth's magnetosphere, Rev. Geophys., 17, 640-656, 1979.

Rème, H., Bosqued, J. M., Sauvaud, J. A., Cros, A., Dandouras, J., Aoustin, C., Bouyssou, J., Camus, Th., Cuvilo, J., Martz, C., Médale, J. L., Perrier, H., Romefort, D., Rouzaud, J., d'Uston, D., Möbius, E., Crocker, K., Granoff, M., Kistler, L. M., Popecki, M., Hovestadt, D., Klecker, B., Paschmann, G., Scholer, M., Carlson, C. W., Curtis, D. W., Lin, R. P., McFadden, J. P., Formisano, V., Amata, E., Bavassano- Cattaneo, M. B., Baldetti, P., Belluci, G., Bruno, R., Chionchio, G., di Lellis, A., Shelley, E. G., Ghielmetti, A. G., Lennartsson, W., Korth, A., Rosenbauer, U., Lundin, R., Olsen, S., Parks, G. K., McCarthy, M., and Balsiger, H.: The Cluster Ion Spectrometry (CIS) Experiment, Space Sci. Rev., 79, 303-350, 1997.

Rostoker, G., Samson, J., Creutzberg, F., Hughes, T., McDiarmid, D., McNamara, A., Jones, A. V., Wallis, D., and Cogger, L.: CANOPUS-A ground based instrument array for remote sensing the high latitude ionosphere during the ISTP/CGS program, Space Sci. Rev., 71, 734-760, 1995.

Ruohoniemi, J. M. and Baker, K. B.: Large-scale imaging of highlatitude convection with Super Dual Auroral Radar Network HF radar observations, J. Geophys. Res., 103, 20 797-20 811, 1998.

Shiokawa, K., Baumjohann, W., Haerendel, G., Paschmann, G., Fennel, J. F., Friis-Christensen, E., Luhr, H., Reeves, G. D., Russell, C. T., Sutcliffe, P. R., and Takahashi, K.: High-speed ion flow, substorm current wedge, and multiple Pi 2 pulsations, J. Geophys. Res., 103, 4491-4507, 1998.
Slavin J. A., Lepping, R. P., Gjerloev, J., Fairfield, D. H., Hesse, M., Owen, C. J., Moldwin, M. B., Nagai, T., Ieda, A., and Mukai, T. Geotail observations of magnetic flux ropes in the plasma sheet, J. Geophys. Res., 108, 1015-1032, 2003.

Slavin J. A., Tanskanen, E. I., Hesse, M., Owen, C. J., Dunlop, M. W., Imber, S., Lucek, E. A., Balogh, A., and Glassmeier, K.-H.: Cluster observations of traveling compression regions in the near-tail, J. Geophys. Res., 110, A06207, doi:10.1029/2004JA010878, 2005.

Smith, C. W., Acuña, M. H., Burlaga, M. F., L'Heureux, J., Ness, N. F., and Scheifele, J.: The ACE Magnetic Fields Experiment, Space Sci. Rev., 86, 613-632, 1998.

Stern, D. P.: The origins of Birkeland currents, Rev. Geophys., 21, 125-138, 1983.

Stone, E. C., Frandsen, A. M., Mewaldt, R. A., Christian, E. R., Margolies, D., Ormes, J. F., and Snow, F.: The Advanced Composition Explorer, Space Sci. Rev., 86, 1-22, 1998.

Taguchi, S., Slavin, J. A., Kiyohara, M., Nosé, M., Reeves, G. D., and Lepping, R. P.: Temporal relationship between midtail traveling compression regions and substorm onset: Evidence for near-Earth neutral line formation in the late growth phase, J. Geophys. Res., 103, 26607-26612, 1998.

Tsyganenko, N. A. and Stern, D. P.: Modeling the global magnetic field of the large-scale Birkeland current systems, J. Geophys. Res., 101, 27 187-27 198, 1996.

Wilken, B., Axford, W. I., Daglis, I., Daly, P., Güttler, W., Ip, W. H., Korth, A., Kremser, G., Livi, S., Vasyliunas, V. M., Woch, J., Baker, D., Belian, R. D., Blake, J. B., Fennell, J. F., Lyons, L. R., Borg, H., Fritz, T. A., Gliem, F., Rathje, R., Grande, M., Hall, D., Kecsueméty, K., McKenna-Lawlor, S., Mursula, K., Tanskanen, P., Pu, Z., Sandahl, I., Sarris, E. T., Scholer, M., Schulz, M., Sørass, F., and Ullaland, S.: RAPID, The Imaging Energetic Particle Spectrometer on Cluster, Space Sci. Rev., 79, 399-473, 1997. 